Nishan Goudsouzian MD, ${ }^{*}$ Sephali Chakravorti PhD, ${ }^{\dagger}$ William Denman MB CHB FRCA, ${ }^{*}$ Ann Schwartz CRNA, ${ }^{*}$ Hong-Seuk Yang $M D,{ }^{*} D$. Ryan Cook $\mathrm{MD}^{\dagger}$

\title{
Prolonged mivacurium infusion in young and elderly adults
}

Purpose: This study was designed to evaluate pharmacodynamically and pharmacokinetically if the cis-cis isomer of mivacurium contributed to neuromuscular block during prolonged infusions lasting more than four hours in young adult and elderly ( $>60 \mathrm{yr}$ ) patients.

Methods: The mechanomyogramic neuromuscular response of the adductor pollicis was recorded in 32 adults 18-59 yr. and 19 elderly ( $>60 \mathrm{yr}$.) patients during $\mathrm{N}_{2} \mathrm{O}: \mathrm{O}_{2}$ :opioid anaesthesia. The mivacurium infusion rate was adjusted to maintain single twitch depression at $95 \pm 4 \%$ of control. Blood samples were taken every 30 min to determine the plasma concentration of cis-cis isomer of mivacurium. At the end of the surgical procedure, patients were allowed to recover spontaneously to at least $25 \%$ of control twitch response.

Results: The mean mivacurium infusion requirement to maintain $97 \pm 1$ (mean \pm SD)\% depression of the twitch response was $6.0 \pm 0.4 \mu \mathrm{g} \cdot \mathrm{kg}^{-1} \cdot \mathrm{min}^{-1}$ in young adults, and $4.3 \pm 0.3 \mu \mathrm{g} \cdot \mathrm{kg}^{-1} \cdot \mathrm{min}^{-1}$ in elderly patients $(P<0.001)$. The infusion requirement in patients with low plasma cholinesterase activity was the lowest $2.4 \pm 1.2$ $\mu \mathrm{g} \cdot \mathrm{kg}^{-1} \mathrm{~min}^{-1}$. Plasma cis-cis isomer concentrations reached peak levels within one-two hours and remained relatively constant throughout the duration of infusion even in patients with low cholinesterase activity. There was no relationship between duration of infusion, plasma concentrations of cis-cis isomer and the early recovery indices of mivacurium (up to 25\%). Neuromuscular transmission recovered adequately with or without antagonism in all patients.

Conclusion: When the mivacurium infusion was titrated to maintain $95 \pm 4 \%$ twitch depression, the plasma concentration of the cis-cis isomer did not increase during prolonged infusions (four hours) and neuromuscular transmission recovers satisfactorily.

Objectif : Cette étude pharmacodynamique et pharmacocinétique visait à déterminer si l'isomère cic-cis du mivacurium contribuait au bloc neuromusculaire pendant des perfusions de quatre heures et plus, chez des jeunes adultes et chez des sujets plus âgés ( $>60$ ans).

Méthodes : La réponse mécanomyographique neuromusculaire a été enregistrée à l'adducteur du pouce chez 32 patients adultes de 18 à 59 ans et chez 19 patients plus âgés ( $>60$ ans) pendant une anesthésie associant N2O/O2 à un morphinique. La vitesse de perfusion du mivacurium était réglée de façon à maintenir un twitch sous $95 \pm 4 \%$ du contrôle. La concentration plasmatique de l'isomère cis-cis du mivacurium était déterminée sur des échantillons de sang prélevés aux $30 \mathrm{~min}$. Une fois la chirurgie terminée, on laissait les patients récupérer spontanément jusqu'à une réponse d'au moins $25 \%$ au twitch.

Résultats : La perfusion moyenne de mivacurium nécessaire pour maintenir la réponse au twitch sous $97 \pm 1 \%$ (moyenne \pm ÉT) était de 6,0 $\pm 0,4 \mu \mathrm{g} \cdot \mathrm{kg}^{-1} \cdot \mathrm{min}^{-1}$ chez les jeunes adultes et de $4,3 \pm 0,3 \mu \mathrm{g} \cdot \mathrm{kg}^{-1} \cdot \mathrm{min}^{-1}$ chez les patients plus âgés $(P<0,001)$. Les patients dont l'activité de la cholinestérase plasmatique était faible avaient besoin de la vitesse de perfusion la plus basse $2,4 \pm 1,2 \mu \mathrm{g} \cdot \mathrm{kg}^{-1}$. Les concentrations plasmatiques de l'isomère cis-cis ont atteint un maximum en moins de deux heures et sont demeurées à peu près constantes pendant la durée de la perfusion même chez les patients dont l'activité de la cholinestérase plasmatique était faible. II riy avait pas de relation entre la durée de la perfusion, la concentration plasmatique de l'isomère cis-cis et les indices précoces de récupération (jusqu'à 25\%). Tous les patients ont récupéré leur fonction neuromusculaire adéquatement avec ou sans antagonisme. Conclusion : Lorsqu'une perfusion de mivacurium est titrée de façon à maintenir le twitch abaissé à $95 \pm 4 \%$, la concentration plasmatique de l'isomère cis-cis n'augmente pas même si la perfusion se prolonge (quatre heures) et la transmission neuromusculaire récupère de façon satisfaisante.

From the Department of Anesthesia and Critical Care, Massachusetts General Hospital, Harvard Medical School, Boston, MA* and Department of Anesthesiology, Children's Hospital, University of Pittsburgh School of Medicine, Pittsburgh, PA'.

This study was supported in part by a grane from Burroughs Wellcome Co.

Address correspondence to: Nishan G. Goudsouzian MD, Department of Anesthesia, Massachusetts General Hospital, Boston, MA

02114, USA; Phone: 617-726-8800; Fax: 617-726-7536.

Accepted for publication June 10, 1997. 
$M$ IVACURIUM is a mixture of three stereoisomers (cis-trans, trans-trans and cis-cis). The cis-trans and trans-trans isomers are the potent neuromuscular blocking components constituting $94 \%$ of the mixture, with in-vivo half-lives of about two $\mathrm{min}$. The cis-cis isomer has a half-life of $53 \mathrm{~min},{ }^{1}$ and has about one- tenth the neuromuscular blocking potency of the other two. Because of its longer half-life, it is feasible that during extended administration of mivacurium the plasma concentration of this isomer would increase and prolong the recovery from neuromuscular block.

Previous studies with mivacurium infusions have been limited to $2.5 \mathrm{hr}$ or less. ${ }^{2,3}$ Therefore, the effect of the cis-cis isomer has not been fully evaluated. We compared mivacurium infusion requirements, plasma cis-cis isomer concentration and the recovery of neuromuscular transmission during short (one-three hours) or long term ( $24 \mathrm{hr}$.) infusions in healthy young adult and elderly adult surgical patients. The overall clinical purpose of this clinically based study was to determine if the cis-cis isomer contributed to neuromuscular block in young and elderly adults during prolonged (four hour) infusion of mivacurium.

\section{Methods}

\section{Patient selection}

This open label study was performed at the Massachusetts General Hospital with the approval of the Institutional Human Studies Committee. Written informed consent was obtained from 51 ASA physical status I or II patients undergoing low-to-moderate risk surgical procedures of variable duration. They were assigned to one of three groups based on age and the expected duration of surgery:

Group A: 12 patients $18-59$ yr. with an expected surgical procedure 1-3 hr (control).

Group B1: 20 patients 18-59 yr. with an expected surgical procedures $>4 \mathrm{hr}$.

Group B2: 20 patients $z 60$ yr. with an expected surgical procedures $>4 \mathrm{hr}$.

Patients with a history of malignant hyperthermia, unusual sensitivity to neuromuscular blocking agents, or receiving drugs that affect neuromuscular transmission such as aminoglycoside antibiotics were excluded. Patients with a body weight $50 \%$ or more above their predicted ideal weight were also excluded.

During intravenous insertion blood samples were taken to determine cholinesterase activity $(\mathrm{ChE})$, dibucaine number (DN), and a control for mivacurium isomer concentration. In the operating room, ECG, pulse oximeter, noninvasive blood pressure, and capnometer were used for routine monitoring. Patients were premedicated with $1-2 \mathrm{mg}$ midazolam and anaesthesia was induced with $5-7 \mathrm{mg} \cdot \mathrm{kg}^{-1}$ thiopentone or $2-5 \mathrm{mg} \cdot \mathrm{kg}^{-1}$ propofol, and maintained with $\mathrm{N}_{2} \mathrm{O}: \mathrm{O}_{2}$ and opioids (fentanyl or morphine) as deemed necessary. After induction, a second intravenous catheter was inserted for blood sampling on the contralateral arm to the mivacurium infusion. Ventilation was adjusted to maintain $\mathrm{P}_{\mathrm{ET}} \mathrm{CO}_{2} 32-40 \mathrm{~mm} \mathrm{Hg}$. Oesophageal temperature was measured and maintained at $235.5^{\circ} \mathrm{C}$.

Neuromuscular monitoring was performed by measuring the force of contraction of the adductor pollicis. Indirect supramaximal single twitch stimuli $(0.2 \mathrm{msec})$ were applied at $0.15 \mathrm{~Hz}$ to the ulnar nerve at the wrist and the force of contraction was determined by a Grass FT10 transducer and recorded on a Grass polygraph. Single twitch stimulation was used throughout the procedure except during neuromuscular recovery when train-of-four stimuli at $0.1 \mathrm{~Hz}$ were used. Onset maximum and maintenance block were determined using the initial baseline response to single twitch stimulation. Recovery was determined using the maximum, stable twitch height $\left(\mathrm{T}_{1}\right)$ after discontinuation of mivacurium infusion (and possible antagonism of residual block) as the baseline for comparison.

After the establishment of a stable twitch response for at least three $\mathrm{min}$ a bolus dose $0.15 \mathrm{mg} \cdot \mathrm{kg}^{-1}$ mivacurium was given $i v$. When the maximum effect of this dose was achieved, tracheal intubation was performed. When the twitch response recovered to at least $5 \%$ of control, a mivacurium infusion was started at $10 \mu \mathrm{g} \cdot \mathrm{kg}^{-1} \cdot \mathrm{min}^{-1}$. The infusion rate was adjusted to maintain the twitch depression at $95 \pm 4 \%$. On average, $15-20 \mathrm{~min}$ were required to adjust the infusion rate to the desired level. One half-hour after the start of infusion and at $30 \mathrm{~min}$ intervals thereafter, a $5 \mathrm{ml}$ blood sample was taken from a vein in the arm contralateral to the infusion. Towards the end of the surgical procedure, the mivacurium infusion was discontinued, a mivacurium plasma sample was obtained and neuromuscular recovery was allowed to occur spontaneously. All patients recovered to at least $25 \%\left(\mathrm{~T}_{1}\right)$ of control. Thereafter, if recovery was prolonged such that it would interfere with operating room schedules, antagonism of residual neuromuscular block was carried out with $10 \mu \mathrm{g} \cdot \mathrm{kg}^{-1}$ glycopyrrolate and $30-50 \mu \mathrm{g} \cdot \mathrm{kg}^{-1}$ neostigmine. In 26 spontaneously recovering patients, additional cis-cis mivacurium samples were taken when the twitch response had recovered to $50 \%$ and $95 \%$ of the initial control.

The $5 \mathrm{ml}$ blood samples collected for the determination of mivacurium isomers were added within $10 \mathrm{sec}$ to $0.1 \mathrm{ml}$ phospholine iodide $1 \%$ in a test tube containing EDTA and mixed thoroughly. The blood samples were 
then centrifuged and the plasma decanted and frozen. The frozen plasma samples were shipped in dry ice to the University of Pittsburgh for determination of mivacurium isomers. The cis-cis isomer of mivacurium was separated from plasma samples by solid phase using $\mathrm{Cl}$ 8-bond elute columns. The extracts were chromatographed (HPLC) on a Regis C18-column ( 3 micron spherisorb packing) 5 $\mathrm{cm} \times 4.6 \mathrm{~mm}$ i.d. The mobile phase was $0.03 \mathrm{M}$ phosphate buffer $60 \%$, pH 3.0 containing $0.0003 \mathrm{M}$ tetramethyl ammonium hydrozide and acetonitrile $40 \%$. A sensitive spectofluometric detector (Spectra-Vision FD300 ) was used with excitation and emission wavelengths at $235 \mathrm{~nm}$ and $320 \mathrm{~nm}$ respectively. ${ }^{4}$ The sensitivity of the assay was within $5 \mathrm{ng} \cdot \mathrm{ml}^{-1}$.

Data are presented as mean ( \pm SD) unless otherwise specified. Analysis of the differences in infusion rate requirements and recovery parameters among the groups was performed using pairwise $t$ tests with DunnSidak correction. The latter correction was used to test the joint significance of the several pairwise comparisons. ${ }^{5,6}$ The difference between infusion requirements was analyzed by ANOVA. Weighted linear regression analysis was performed for each patient between infusion time and infusion rate vs. plasma cis-cis isomer levels. These data were weighted to equalize the effect on each subject $v s$ the number of observations. The repeated measured of the analysis of covariance was performed by using SAS Proc GLM (SAS Institute, Cary, N.C.). For the comparisons between groups $\mathrm{B} 1$ and $\mathrm{B} 2$, the twosample $t$ test with Bonferroni correction for multiple tests was used. Regression analysis was performed to evaluate whether the plasma cis-cis isomer concentration at the termination of infusion had any influence on the recovery parameters of mivacurium. Statistical significance was designated at a $P$ value of $<0.05$.

\section{Results}

Fifty-one ASA 1 and 2 patients, 18-81 yr., were evaluated as per protocol. The mean age of the 12 group $A$ patients was $42.9 \pm 14.2 \mathrm{yr}$. and their weight was 73.8
TABLE I Plasma cholinesterase activity and dibucaine number of patients within the normal range (mean $\pm S D$ ) $A, B_{1}$ and $C_{2}$, and those with decreased activity (X)

\begin{tabular}{lll}
\hline & $C h E\left(u \cdot L^{-1}\right)$ & $D N(\%)$ \\
\hline A $(n=10)$ & $5216 \pm 1381$ & $78.5 \pm 7$ \\
B1 $(n=19)$ & $5187 \pm 1251$ & $81.8 \pm 3.3$ \\
B2 $(n=17)$ & $4774 \pm 1310$ & $80.5 \pm 5.1$ \\
X $(n=5)$ & $1074 \pm 637^{\star}$ & $41.1 \pm 20.4^{\star}$ \\
\hline
\end{tabular}

${ }^{*} P<0.01$ compared with the other three groups.

Normal range ChE 3800-8800 u. $\mathrm{l}^{-1}$ and DN 77-83\%.

$\pm 13.9 \mathrm{~kg}$. The mean age of groups $\mathrm{Bl}(\mathrm{n}=20)$ and $\mathrm{B} 2$ $(n=19)$ were $40.5 \pm 13.7 \mathrm{yr}$, and $66.1 \pm 6.4 \mathrm{yr}$., and their corresponding weights were $79.1 \pm 19.8 \mathrm{~kg}$ and $85.9 \pm 14.6 \mathrm{~kg}$ respectively. The data of one patient in the elderly group (B2) were not used because surgery ended in less than $2.5 \mathrm{~h}$, hence $\mathrm{n}=19$ in this group. There were differences $(P<0.05)$ between the age of group B2 patients when compared with Group A and Bl. There was no difference in the patients' weight of each group.

During the study we encountered five patients with plasma cholinesterase and dibucaine levels $20 \%$ below the lower limit provided by laboratories performing the analysis (Normal range RE 3800-8800, DN 77-83\%, Metpath, Teterboro, N.J.). Data from these patients were analyzed separately as subgroup $(\mathrm{X})$. The cholinesterase activity and the dibucaine number of the patients are summarized in Table I. In the 46 patients with normal cholinesterase activity, $0.15 \mathrm{mg} \cdot \mathrm{kg}^{-1}$ mivacurium produced $98.4 \pm 0.9 \%$ (range $78-100 \%$ ) suppression of the twitch response in 2-9 min. Neuromuscular transmission recovered to $5 \%$ of control response in $14.5 \pm \mathrm{min}$ ). Elderly patients (group B2) recovered more slowly than the young adults by about three minutes $(P<0.05)$ (Table II).

The mean mivacurium infusion requirement to maintain comparable twitch suppression was similar in patients in group $\mathrm{A}$ and $\mathrm{Bl}$, whereas, in the elderly

TABLE II Effect of initial $0.15 \mathrm{mg} \cdot \mathrm{kg}^{-1}$ mivacurium

\begin{tabular}{llll}
\hline & Max. neuromuscular & Time to max. suppression & Recovery to 5\% (min) \\
\hline & suppression $(\%)$ & (min) & \\
A & $99.3 \pm 0.5$ & $3.7 \pm 0.4$ & $14.8 \pm 2.5$ \\
B1 & $96.9 \pm 1.4^{*}$ & $4.7 \pm 0.3$ & $12.7 \pm 1.4^{\dagger}$ \\
B2 & $99.1 \pm 0.7$ & $4.4 \pm 0.5$ & $16.1 \pm 1.9^{\dagger}$ \\
X & $100^{*}$ & $3.3 \pm 0.5$ & $23.2 \pm 3.6^{\dagger}$ \\
\hline
\end{tabular}

${ }^{*} P<0.05$ between groups $\mathrm{B} 1$ and $\mathrm{X}$.

$\dagger P<0.05$ between groups $B 1$ and $B 2$.

${ }_{\ddagger} P<0.05$ between group $\mathrm{X}$ and $\mathrm{A}, \mathrm{B} 1, \mathrm{~B} 2$. 


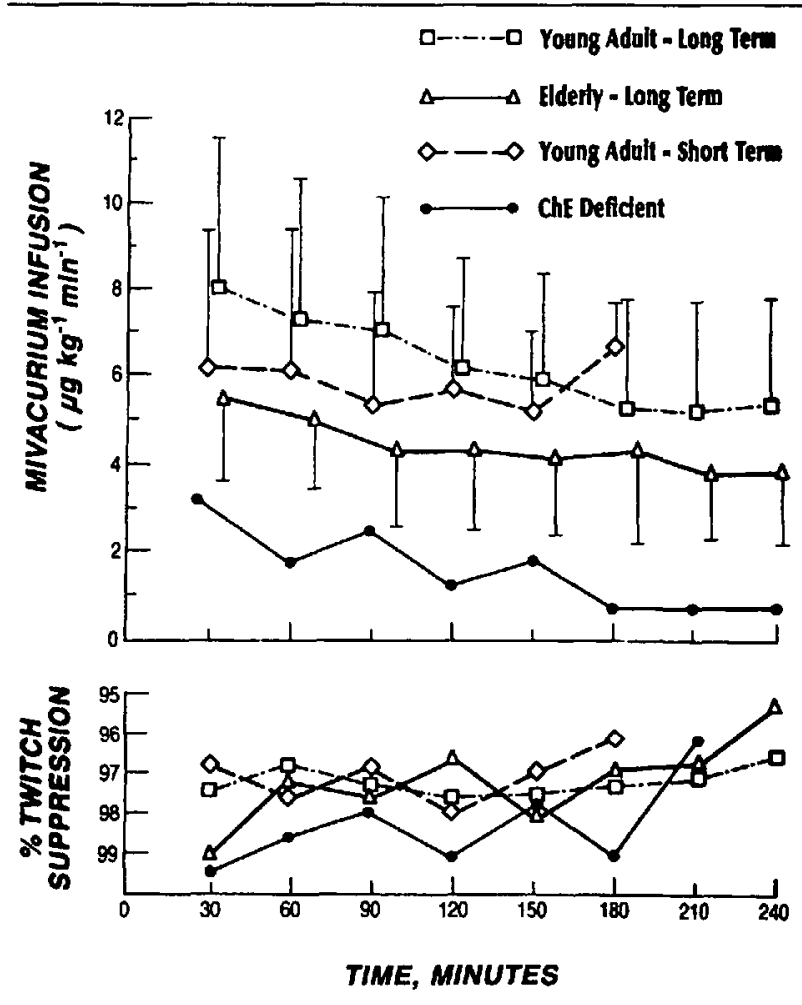

FIGURE 1 Mean \pm SD mivacurium infusion requirements to maintain $90-99 \%$ depression of twitch response and the corresponding twitch suppression in the four groups of patients (data of the cholinesterase deficient parients are the medians).

patients (group B2) the infusion requirement at the periods $30-240 \mathrm{~min}$ was about $25 \%$ lower than in the other two groups $(P<0.001)$ (Table III, Figure 1$)$ despite similar suppressions of the twitch response $(97.1 \%)$. Patients with low ChE activity had the lowest infusion requirements $(P<0.0001)$. There were no statistical differences of the percent twitch suppressions among the four groups of patients (Figure 1).

Within the three groups of patients (A, Bl, and B2) with normal ChE activity, in 35 patients, the infusion requirement remained fairly constant from the initial infusion adjustment to the end of the surgical procedure. In 11 patients, however, the infusion requirement decreased $>30 \%$ from the initial adjusted rate $(30-60 \mathrm{~min})$ to that rate required to maintain the same degree of relaxation before termination of the infusion. One of these 11 patients was from group $A$, six were from group $B 1$, and four were from group B2. A comparison was made between the subgroup which showed decreasing infusion rates $(n=11)$ and the patients in the other 3 groups (A, B1, and B2) that remained at fairly constant rates (Table IV). There was no difference between these two subgroups of patients viz a viz demographics, plasma ChE, effect of initial mivacurium bolus, and the mean twitch suppression. Upon discontinuation of the mivacurium infusion, the two subgroups of patients recovered to $25 \%$ of control at similar rates. The end plasma cis-cis isomer concentrations and the frequency of need for reversal were higher in the decreasing infusion subgroup, but the difference was not significant.

All patients were allowed to recover to at least $25 \%$ of control $T_{1}$ response. The mean $T_{1}$ response at the termination of the infusion was $5.2 \pm 2.1 \%$. They recovered to $25 \%$ of control in $9.4 \pm 1 \mathrm{~min}$ (Table V). In patients with normal ChE activity, we were able to observe spontaneous recovery until $\mathrm{T}_{1}$ reached $95 \%$ in 25 patients. These patients recovered to $95 \%$ of $T_{1} /$ control in $21 \pm$ $4 \mathrm{~min}$ and achieved a train-of- four ratio of 0.75 in $24 \pm$ $7 \mathrm{~min}$. The mean plasma cis-cis isomer concentrations at the end of the infusion in the group needing reversal was $67 \pm 37 \mathrm{ng} \cdot \mathrm{ml}^{-1}$ which was not different from the group with spontaneous recovery $80 \pm 28 \mathrm{ng} \cdot \mathrm{ml}^{-1}$. At the end of the surgical procedure, all patients had return of the twitch response to control and demonstrated strong hand grip and head lift in the recovery room.

Plasma cis-cis isomer concentration reached peak levels within 1-2 hr and remained relatively constant throughout the duration of infusion (Figure 2).

TABLE III Mivacurium infusion rates to maintain 90-99\% twitch suppression.

\begin{tabular}{llll}
\hline & $\begin{array}{l}\text { Infusion rate } \\
\mu g \cdot \mathrm{kg}^{-1} \mathrm{~min}^{-1}\end{array}$ & $\begin{array}{l}\text { Mean cis-cis isomer } \\
\text { concentration }\left(\mathrm{ng} \cdot \mathrm{mt}^{-1}\right)\end{array}$ & Duration of infusion (min) \\
\hline $\mathrm{A}$ & $6.0 \pm 2.7$ & $95.4 \pm 41.5$ & $144.7 \pm 15.4$ \\
$\mathrm{~B} 1$ & $5.9 \pm 2.5$ & $109.9 \pm 80$ & $386.9 \pm 44.8$ \\
$\mathrm{~B} 2$ & $4.5 \pm 1.0^{*}$ & $77.4 \pm 35.8$ & $326.2 \pm 43.4$ \\
$\mathrm{X}$ & $2.4 \pm 1.2^{\dagger}$ & $108.1 \pm 185$ & $195 \pm 76.1$ \\
\hline
\end{tabular}

${ }^{*} P<0.001$ between $\mathrm{B} 2$ and $\mathrm{A}, \mathrm{B} 1$.

${ }^{\dagger} P<0.0001$ between $\mathrm{X}$ and $\mathrm{A}, \mathrm{B} 1, \mathrm{~B} 2$.

There was no significant difference in the mean depression of the twitch response among the four groups. 


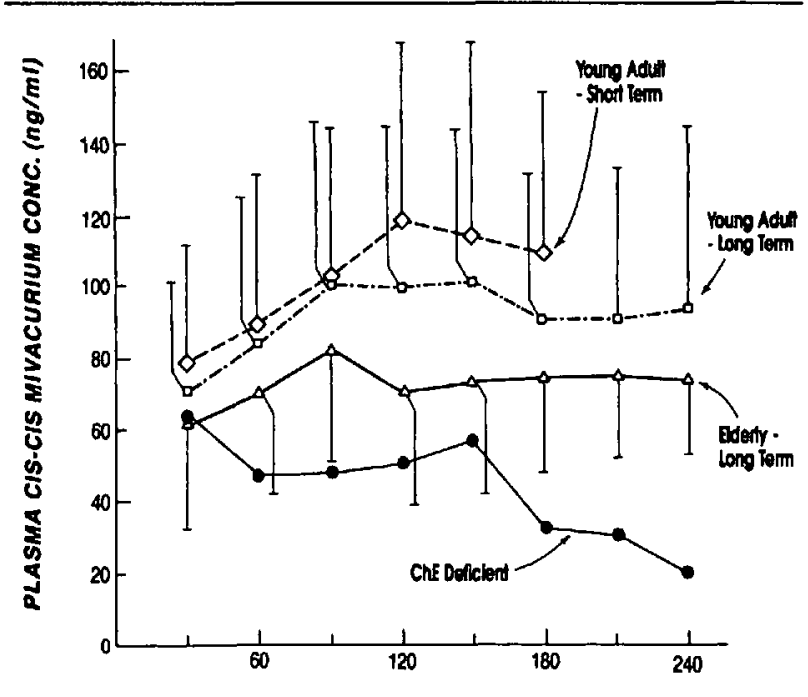

FIGURE 2 The mean \pm SD average concentration-time of cis-cis isomer of mivacurium in the four groups of patients (data of the cholinesterase deficient patients are the medians).
The weighted regression analysis, performed to determine whether the duration of infusion influenced plasma mivacurium cis-cis level (time trend), showed no correlation between duration of infusion and plasma cis-cis mivacurium concentration in patients with prolonged infusion ( $\mathrm{Bl}$ and $\mathrm{B} 2$ ).

There was a positive relationship between infusion rate and cis-cis mivacurium concentration $(P<0.001)$. In general, every $1 \mu \mathrm{g} \cdot \mathrm{kg}^{-1} \cdot \mathrm{min}^{-1}$, increase in infusion rate led to $4.2-4.5 \mathrm{ng} \cdot \mathrm{ml}^{-1}$ increase in plasma cis-cis isomer concentration. The difference between the two groups ( $\mathrm{Bl}$ and $\mathrm{B} 2$ ) on cis-cis concentration can be explained by the difference in the infusion rate between the two groups.

The plasma cis-cis mivacurium concentration at discontinuation of infusion was lower in elderly patients (B2) than in young adults $(\mathrm{B} 1)(P<0.01)$. However, the early recovery times (to $25 \%$ ) were not different among the three groups. Since all patients were allowed to

TABLE IV Comparison of patients with constant $v$ s decreasing mivacurium infusion *

\begin{tabular}{|c|c|c|}
\hline$n$ & $\begin{array}{l}\text { Constant } \\
35\end{array}$ & $\begin{array}{l}\text { Decreasing* } \\
11\end{array}$ \\
\hline $\begin{array}{l}\text { Age (yr.) } \\
\text { Weight (kg) } \\
\text { ChE (u.L-1) } \\
\text { DN }(\%)\end{array}$ & $\begin{array}{l}49.7 \pm 15.8 \\
78.6 \pm 26.5 \\
4924 \pm 1572 \\
80.1 \pm 1.8\end{array}$ & $\begin{array}{l}53 \pm 15 \\
88 \pm 11 \\
5365 \pm 1222 \\
81.9 \pm 6.9\end{array}$ \\
\hline $\begin{array}{l}\text { Effect of } 0.15 \mathrm{mg} \cdot \mathrm{kg}^{-1} \\
\text { Max. Twitch suppression (\%) } \\
\text { Recovery to } 5 \%(\mathrm{~min})\end{array}$ & $\begin{array}{l}98.5 \pm 1.4 \\
16.0 \pm 4.5\end{array}$ & $\begin{array}{l}97.4 \pm 3.9 \\
10.2 \pm 4.9\end{array}$ \\
\hline $\begin{array}{l}\text { Infusion } \\
\text { Duration of infusion (min) } \\
\text { Mean Infusion rate }\left(\mu \mathrm{g} \cdot \mathrm{kg}^{-1} \cdot \mathrm{min}^{-1}\right) \\
\text { Mean twitch suppression }(\%)\end{array}$ & $\begin{array}{l}330 \pm 84 \\
5.4 \pm 0.01 \\
96.2 \pm 3.2\end{array}$ & $\begin{array}{l}27.2 \pm 78 \\
5.5 \pm 0.8 \\
97.3 \pm 1.3\end{array}$ \\
\hline $\begin{array}{l}\text { Recovery } \\
\text { Tl at the end \% of infusion } \\
\text { Cis-cis concentration at end (ng. } \mathrm{ml}^{-1} \text { ) } \\
\text { Recovery to } 25 \% \text { (min) } \\
25-75 \% \text { (min) } \\
\text { Recovery to } 95 \% \text { (min) } \\
\text { Number patients reversed/total } \\
\text { Tl at Reversal }\end{array}$ & $\begin{array}{l}5.3 \pm 0.03 \\
83.8 \pm 22.8 \\
6.8 \pm 0.21 \\
9.0 \pm 0.1 \\
20.8 \pm 0.2 \\
7 / 35 \\
75.1 \pm 44.9\end{array}$ & $\begin{array}{l}7.5 \pm 1.8 \\
125.6 \pm 100.9 \\
7.8 \pm 2.1 \\
10.1 \pm 19 \\
21.7 \pm 5.2 \\
4 / 11 \\
40.7 \pm 13.4\end{array}$ \\
\hline
\end{tabular}

*Decreasing infusion rate was defined as a subgroup in which the infusion rate drifted downward by $>30 \%$ from the initial rate after adjustment.

TABLE V End infusion cis-cis mivacurium concentration and the corresponding recovery variables

\begin{tabular}{lcccccc}
\hline & $\begin{array}{c}\text { Cis-cis at the end } \\
\left(\mathrm{ng} \cdot \mathrm{ml}^{-1}\right)\end{array}$ & $\begin{array}{c}\text { Infusion rate at } \\
\text { the end }\end{array}$ & $\begin{array}{c}\text { Tl at the end } \\
\text { of infusion }(\%)\end{array}$ & $\begin{array}{c}\text { Recovery to 25\% } \\
(\mathrm{min})\end{array}$ & $\begin{array}{c}5-25 \% \text { recovery } \\
(\mathrm{min})\end{array}$ & $\begin{array}{c}\text { RI, 25-75\% } \\
(\mathrm{min})\end{array}$ \\
\hline $\mathrm{A}$ & $88.2 \pm 47.6$ & $5.5 \pm 2.2$ & $4.7 \pm 5.2$ & $8.6 \pm 4.9$ & $7.7 \pm 3.8$ & $10.6 \pm 4.8$ \\
B1 & $97.5 \pm 44.8^{*}$ & $5.6 \pm 2.1$ & $4.2 \pm 4.1$ & $9.1 \pm 5.5$ & $6.6 \pm 2.9$ & $9.9 \pm 5.5$ \\
B2 & $62.8 \pm 28.1^{\star}$ & $4.2 \pm 1.4$ & $6.7 \pm 6.9$ & $9.9 \pm 6.3$ & $9 \pm 3.4$ & $9.6 \pm 3.1$ \\
\hline
\end{tabular}

${ }^{*} P=0.006$ between $\mathrm{B} 1$ and $\mathrm{B} 2$. 
recover to at least $25 \%$ of $\mathrm{T}_{1} /$ control and in 43 patients recovered to $75 \%$ of $\mathrm{T}_{1} /$ control, a correlation analysis was carried out between cis-cis mivacurium levels and $5-25 \%$ and $25-75 \% \mathrm{Tl}$ recovery parameters. A negative correlation was noted $(r=-0.33-0.41, P<0.025)$, indicating that patients with the higher cis-cis levels recovered faster than the ones with lower levels.

Analysis of mean mivacurium infusion rates $v s$ plasma cholinesterase activity yielded a positive correlation $(\mathrm{r}=0.69, P=0.0001)$. Patients with the higher cholinesterase levels required higher infusion rates.

In the 26 spontaneously recovering patients that we obtained plasma samples during recovery, the end ciscis concentration was $81.7 \pm 7.7 \mathrm{ng} \cdot \mathrm{ml}^{-1}$. When the $T_{1}$ of train-of-four twitch had recovered to the initial $50 \%$ and $95 \%$ of control, the concentrations were $59.4 \pm$ $8.7 \mathrm{ng} \cdot \mathrm{ml}^{-1}$ and $39.5 \pm 6.1 \mathrm{ng} \cdot \mathrm{ml}^{-1}$ respectively, $68 \%$ and $46 \%$ of the end concentration after $14.6 \pm 7.6$ and $24.1 \pm 9.3 \mathrm{~min}$ following discontinuation of infusion.

\section{Patients with Cholinesterase Deficiency (Subgroup X)}

Five patients in this study had plasma cholinesterase concentrations $20 \%$ below the lowest normal range values reported by our laboratory (two were women, three men, all Caucasians). Their data were analyzed separately. Two patients were from group $\mathrm{A}$, one from $\mathrm{Bl}$, and two from B2. The mean cholinesterase activity of these patients was $1074 \pm 637 \mathrm{u} \cdot \mathrm{L}^{-1}$, and their mean dibucaine number was $41.1 \pm 20.4 \%$ (Table I). The twitch recovery of these patients to $5 \%$ of control following the initial $0.15 \mathrm{mg} \cdot \mathrm{kg}^{-1}$ mivacurium was about six minutes longer than the other three groups $(P<0.05)$ occurring in $23.2 \pm 3.6 \mathrm{~min}$ (Table II). The average mivacurium infusion requirements was one-third to one-half that of the other groups $(P<0.0001)$ (Table III, Figure 1). Their mean cis-cis concentration was $108 \pm 185$, not different from the other three groups. Because of the limited number of cases in this group (5) and the marked variability, we present their data as medians in Figure 2.

Following discontinuation of infusion the recovery of $\mathrm{T}_{1}$ /control to $25 \%$ in these five $\mathrm{ChE}$ deficient patients was $5.1 \mathrm{~min}$ longer than in the other groups (NS). However, the subsequent recovery from infusion was prolonged, so that four of them required reversal. In one patient we waited for full recovery, which took about one hour.

\section{Discussion}

The aim of this study was to evaluate whether the cis-cis isomer concentration increases during prolonged infusion of mivacurium $(>4 \mathrm{hr}$ ) in young adult $(<60 \mathrm{yr}$.) or elderly ( $>60 \mathrm{yr}$.) surgical patients when the mivacurium dose is adjusted to maintain constant neuromuscular relaxation. Our data showed that the plasma concentration did not increase progressively and this isomer was not a cause of delayed neuromuscular recovery.

Since the study was performed in both young and elderly adults, some differences were noted in the neuromuscular dynamic response of these two groups of patients when given mivacurium. We noted that the time for maximum twitch suppression was similar in groups B1 and B2 following a bolus dose $0.15 \mathrm{mg} \cdot \mathrm{kg}^{-1}$ mivacurium, but recovery to $5 \%$ was about three minutes faster in young adults than in the elderly (Table II). The infusion requirement, however, was less in the elderly (Table III) (Figure 1). This is despite the fact that there was no difference in the plasma cholinesterase activity between the two groups (Table I). Our dynamic data showed the same trend that has been noted in studies with mivacurium in elderly and young adults during halothane, isoflurane or $\mathrm{N}_{2} \mathrm{O}: \mathrm{O}_{2}$ opioid anaesthesia. ${ }^{7-9}$ These studies showed that recovery to $5 \%$ following $0.15 \mathrm{mg} \cdot \mathrm{kg}^{-1}$ mivacurium was slower and infusion requirement was less in elderly than in the young. Onset time in our study was longer $(\approx 4-5 \mathrm{~min})$, than reported previously $(2 \mathrm{~min})$. Those studies used repeated train-of-four stimulation, whereas we used single twitch stimulation. ${ }^{7-9}$

In the two previous studies the slower recovery pattern of the elderly as well as the decreased infusion requirements were speculated to be due to decreased plasma cholinesterase activity in the elderly, despite not measuring the cholinesterase levels. ${ }^{7,8}$ In our study, the plasma cholinesterase activity and the dibucaine number were similar in young adults and the elderly. This discrepancy is not surprising since, in the best of circumstances, $48-51 \%$ of the variability in infusion rates in adults can be explained as a function of the variability in plasma cholinesterase activity. ${ }^{10}$ Because cholinesterase hydrolysis is not the only mechanism by which mivacurium would be broken down and cleared, other factors such as redistribution and excretion influence its clearance. Also, the clearance of intermediate and long acting relaxants which are not hydrolyzed by plasma cholinesterase are also prolonged in the elderly. ${ }^{11,12}$

In previous studies of short term infusion of mivacurium at lower total doses $\left(0.9-0.15 \mathrm{mg} \cdot \mathrm{kg}^{-1}\right)_{,}^{1,13,14}$ the highest mean plasma level of mivacurium reported was about $80 \mathrm{ng} \cdot \mathrm{ml}^{-1}$. Our results of long term infusion are comparable with the above mentioned concentration (Table III). In contrast to infusion requirement values which were lower in the elderly we noted that plasma ciscis concentration throughout the infusion period, was not different in elderly and young adults (Tables III, V, Figure 2), but there was a tendency for the cis-cis isomer concentration to be lower in the elderly population. A 
point can be made that the lower cis-cis level in the elderly is a reflection of the lower mivacurium infusion rates in the elderly. These data indicate that the cis-cis isomer does not have a specific effect on the elderly compared with younger adults, nor does it have a tendency to accumulate when given at a rate to maintain adequate clinical relaxation. Also, the early recovery parameters $5-25 \%$ (6.6-9 $\mathrm{min})$ and $25-75 \%$ (9.9-9.6 $\mathrm{min}$ ) following prolonged infusion were only about two minutes longer than previously published studies of single dose or short infusion of mivacurium $(5-25 \%, 4-7.7 \mathrm{~min} ; 25-75 \%$, 4-8.7 $\mathrm{min}) \cdot{ }^{2,7,15}$

In most of our subjects, the mivacurium infusion requirement (following the initial adjustment) remained constant throughout the procedure, as has been reported in other studies. ${ }^{2,3}$ In 11 patients, we noted that, after the initial adjustment, there was $>30 \%$ decrease in the infusion requirement over the course of 3-5 hr infusion. Seven of these patients were young adults while four were $>60$ yr. Recently, during prolonged infusion in neurosurgical patients with $\mathrm{N}_{2} \mathrm{O}: \mathrm{O}_{2}$ and isoflurane $0.2-0.3 \%$ anaesthesia, a decrease in requirements from 7 $\mu \mathrm{g} \cdot \mathrm{kg}^{-1} \cdot \mathrm{min}^{-1}$ to $3-4 \mu \mathrm{g} \cdot \mathrm{kg}^{-1} \cdot \mathrm{min}^{-1}$ over $5-8$ hours of infusion was noted with an approximate $30 \%$ increase in recovery times. ${ }^{16}$ In parients with renal impairment, decreased infusion rates and prolonged recovery was noted. ${ }^{14,17}$ We did not notice any specific trend that could predict decreased requirement, as cholinesterase levels and the effect of the initial $0.15 \mathrm{mg} \cdot \mathrm{kg}^{-1}$ mivacurium were similar between these two subgroups. The final plasma cis-cis concentration was higher in the patients with decreasing requirements but the difference was not statistically significant. Although the initial recovery to $25 \%$ of control following discontinuation of infusion was similar in these two subgroups, the subgroups with the decreasing infusion rate more frequently required reversal ( $P: \mathrm{NS})$ after recovery to $25 \%$. We cannot offer an explanation for this phenomenon. In several patients, the surgical procedures were complex and patients received blood transfusion which was given as packed cells (autologous), and hence was devoid of plasma cholinesterase. These patients also received several litres (3-5) of lactated Ringer's solution which would have led to haemodilution and hence decreased cholinesterase activity. It could be argued that some interference of plasma cholinesterase activity occurred during prolonged infusion or that the biophase binding of mivacurium to the myoneural junction is stronger in these patients. ${ }^{18}$

In this study, performed predominantly on a Caucasian population, we would have expected to encounter one to two patients with mild cholinesterase deficiency (heterozygous). ${ }^{19}$ We encountered five patients, occurring in all groups. Their $\mathrm{ChE}$ concentration ranged from 180 to $1700 \mathrm{u} \cdot \mathrm{L}^{-1}$ and their dibucaine numbers from 8 to $56.9 \%$. These patients, despite the low $\mathrm{ChE}$ level, did not have marked prolonged recovery from the initial $0.15 \mathrm{mg} \cdot \mathrm{kg}^{-1}$ mivacurium compared with those with normal $\mathrm{ChE}(23 \pm 4 \mathrm{~min}$ vs $15 \pm 7 \mathrm{~min})$. However, their infusion requirements were less than half those of the patients with normal activity. As in the elderly and young adults, patients with $\mathrm{ChE}$ deficiency did not show any evidence of accumulation of the cis-cis isomer. The plasma concentrations of cis-cis isomer in these patients at the end of the infusion were lower than that in the patients with normal ChE activity; probably, a reflection of the infusion rates. However, the recovery rates of these patient were slower and four of them required reversal. Initial recovery following infusion termination was not prolonged (to $25 \%$ ) but full recovery was; most required reversal. It can be inferred that the cis-cis isomer is not a factor in recovery from mivacurium in patients with $\mathrm{ChE}$ deficiency.

The lower cis-cis mivacurium at discontinuation of infusion in elderly relative to young adults is probably a reflection of the lower infusion requirements in this group of population. However, early recovery parameters were not different between the groups. The negative correlation between end cis-cis mivacurium concentrations and recovery variables was contrary to the original hypothesis that cis-cis concentrations can prolong recovery from mivacurium. A direct derivation of this observation would be that cis-cis antagonizes the neuromuscular relaxation. However, this would be illogical since there are multiple other factors involved. Another speculation would be that the biophase binding is a more important factor than the absolute cis-cis mivacurium concentration, hence patients requiring lower concentrations had stronger biophasic binding and lesser requirement of mivacurium throughout.

In conclusion, we found that it is safe to administer mivacurium for prolonged surgical procedures (about 4-5 hr), as long as twitch depression is maintained within the clinical range $(90-99 \%$ of control). The plasma concentration of mivacurium cis-cis isomer does not increase progressively, nor does it prolong early recovery. Some patients may show reduced infusion requirements over time.

\section{Acknowledgements}

The authors are indebted to Dr. Sanjay Patel for his time collecting the data, Dr. Neal Weakly for his suggestions and guidance and to Basil Samara $\mathrm{PhD}$, Alan Zaslavsky PhD, and Michael Cheng AM for their assistance in statistical analysis. 


\section{References}

1 Lien CA, Schmith VD, Embree PB, Belmont MR, Wargin WA, Savarese JJ. The pharmacokinetics and pharmacodynamics of the stereoisomers of mivacurium in patients receiving nitrous oxide/opioid/barbiturate anesthesia. Anesthesiology 1994; 80: 1296-302.

2 Ali HH, Savarese J, Embree PB, et al. Clinical pharmacology of mivacurium chloride (BW 1090U) infusion comparison with vecuronium and atracurium. Br J Anaesth 1988; 61: 541-6.

3 Basta SJ. Clinical pharmacology of mivacurium chloride: a review. J Clin Anesth 1992; 4: 153-63.

4 Cook DR, Stiller RL, Weakly JN, Chakravorti S, Brandom $B W$, Welch $R M$. In vitro metabolism of mivacurium chloride (BW B1090U) and succinylcholine. Anesth Analg $1989 ; 68: 452-6$.

5 Sidak Z. Rectangular confidence regions for the means of multivariate normal distributions. Journal of the American Statistical Association 1967; 62: 626-33.

6 Toothaker LE. Multiple Comparisons for Researchers. Newbury Park: Sage Publications, 1991: 37-40.

7 Maddineni VR, Mirakbur RK, McCoy EP, Sharpe TDC. Neuromuscular and haemodynamic effects of mivacurium in elderly and young adult patients. $\mathrm{Br} \mathrm{J}$ Anaesth 1994; 73: 608-12.

8 Platt MW, Munday IT, Merrett KL, Weston MD, Jones $R M$. Mivacurium in young adults and elderly patients. Proceedings of the Anaesthesia Research Society. Br J Anaesth 1994; 73: 263P.

9 Dababa AA, Rebak PH, List WF. A comparison of mivacurium infusion requirements between young and elderly adult patients. Eur J Anaesthesiol 1996; 13: 43-8.

10 Hart PS, McCarthy GJ, Brown R, Lau M, Fisher DM. The effect of plasma cholinesterase activity on mivacurium infusion rates. Anesth Analg 1995; 80: 760-3.

11 Matteo RS, Backus WW, McDaniel DD, Brotherton WP, Abrabam R, Diaz J. Pharmacokinetics and pharmacodynamics of $d$-tubocurarine and metocurine in the elderly. Anesth Analg 1985; 64: 23-9.

12 Lien CA, Matteo RS, Ornstein E, Schwartz AE, DiazJ. Distribution, elimination, and action of vecuronium in the elderly. Anesth Analg 1991: 73: 39-42.

13 Head-Rapson AG, Devlin JC, Parker CJR, Hunter JM. Pharmacokinetics of the three isomers of mivacurium and pharmacodynamics of the chiral mixture in hepatic cirrhosis. Br J Anaesth 1994; 73: 613-8.

14 Head-Rapson AG, Devlin JC, Parker CJR, Hunter JM. Pharmacokinetics and pharmacodynamics of the three isomers of mivacurium in health, in end-stage renal failure and in patients with impaired renal function. Br J Anaesth 1995; 75: 31-6.

15 Devlin JC, Head-Rapson AG, Parker CJR, Hunter JM. Pharmacodynamics of mivacurium chloride in patients with heparic cirrhosis. Br J Anaesth 1993; 71: 227-31.
16 Jellish WS, Thalji ZA, Murdoch JR. Recovery from mivacurium-induced neuromuscular blockade after neurosurgical procedures of long duration. J Clin Anesth 1995; 7: 643-7.

17 Blobner M, Jelen-Esselborn S, Schneider G, et al. Effect of renal function on neuromuscular block induced by continuous infusion of mivacurium. $\mathrm{Br} \mathrm{J}$ Anaesth 1995; 74: $452-4$.

18 Feldman $S$. Biophase binding: its effect on recovery from non-depolarizing neuromuscular block. Anaesthetic Pharmacology Review 1993; 1: 81-7.

19 Whittaker $M$. Plasma cholinesterase variants and the anaesthetist. Anaesthesia 1980; 35: 174-97. 